\title{
Eficiência agronômica de fosfato natural reativo na cultura da soja
}

\author{
Adilson de Oliveira Junior ${ }^{(1)}$, Luís Ignácio Prochnow ${ }^{(1)}$ e Dirceu Klepker ${ }^{(2)}$ \\ (1)Escola Superior de Agricultura Luiz de Queiroz, Departamento de Ciência do Solo, Caixa Postal 09, CEP 13418-900 Piracicaba, SP. \\ E-mail: aojunior@esalq.usp.br, liprochn@esalq.usp.br (2)Embrapa Soja, Setor Experimental de Balsas, Caixa Postal 131, Setor Industrial, \\ CEP 65800-000 Balsas, MA. E-mail: dirceu@embrapabalsas.com.br
}

\begin{abstract}
Resumo - O objetivo deste trabalho foi avaliar a eficiência agronômica relativa de uma fonte de fósforo na cultura de soja [Glycine max (L.) Merrill.]. O superfosfato triplo foi a fonte-padrão, e o fosfato natural reativo Arad foi a fonte testada, ambos aplicados em diferentes doses, em área total ou no sulco de semeadura. Em outubro de 2004, o experimento foi instalado em Balsas, MA, em Latossolo Vermelho-Amarelo distrófico, textura argilosa e baixa disponibilidade de fósforo, conduzido com soja cultivar BRS Sambaíba por três safras (2004/2005 a 2006/2007); a terceira safra foi conduzida sob efeito residual das aplicações anteriores. De forma geral, não foram observadas diferenças quanto à localização da fonte-padrão, ao passo que a localização do fosfato natural reativo Arad reduziu significativamente a eficiência. Quando aplicado a lanço, nos dois primeiros cultivos, o fosfato natural reativo Arad resultou em aproximadamente $76 \%$ de eficiência agronômica relativa, o que demonstra média viabilidade agronômica. Sob efeito residual, a aplicação localizada do superfosfato triplo resultou em resposta semelhante à verificada com a aplicação anual desta fonte, entretanto, $\mathrm{o}$ aumento na eficiência agronômica relativa foi mais acentuado, quando ambas as fontes foram aplicadas a lanço.
\end{abstract}

Termos para indexação: Glycine max, fertilizante fosfatado, fósforo, solo de cerrado.

\section{Agronomic effectiveness of phosphate rock evaluated in soybean crop}

\begin{abstract}
The objective of this work was to evaluate the relative agronomic effectiveness of the application of broadcasted and banded phosphorus rates, testing a standard source (triple superphosphate) and Arad phosphate rock in a soybean crop, in the Balsas, MA, Brazil. The experiment was carried out in October 2004, on a Typic Hapludox, clayey texture and very low available phosphorus, conducted with soybean [Glycine max (L.) Merrill.], cultivar BRS Sambaíba], for three consecutive harvests (2004/2005 to 2006/2007). The third harvest was carried out on residual effect of the previous applications. In general, it was not observed any differences related to the localization of the standard source. In contrast, Arad phosphate rock localization reduced the relative agronomic effectiveness significantly. In the first two harvests, broadcasted Arad phosphate rock resulted in approximately $76 \%$ of relative agronomic effectiveness, showing medium agronomic viability. Under residual effect, banded triple superphosphate resulted in similar response to that obtained with annual application of triple superphosphate, however, the increase in relative agronomic effectiveness was greater when broadcasting both phosphorus sources.
\end{abstract}

Index terms: Glycine max, phosphorus fertilizers, phosphorus, Cerrado soils.

\section{Introdução}

A soja vem sendo cultivada no Brasil desde a década de 50, no entanto, a partir de meados da década de 70, com a obtenção de cultivares adaptadas a baixas latitudes, deu-se início à expansão da fronteira agrícola para a Região Central do Brasil. Nessas áreas, predominam solos com baixa fertilidade química, mas, com relevo e condições climáticas extremamente adequadas ao cultivo. Toda essa região é comumente denominada de
Cerrados e, constitui aproximadamente $25 \%$ da área total do Brasil.

Embora em pequena escala, o cultivo de soja na região de Balsas, ao Sul do Estado do Maranhão, também teve início na década de 70. Na safra 2006/2007, a área cultivada com soja nesse Estado foi de $384.400 \mathrm{ha}$, com produtividade média de $2.820 \mathrm{~kg} \mathrm{ha}^{-1}$ (Conab, 2007). Uma das vantagens dessa região, em relação aos estados do Centro-Oeste, é a possibilidade de escoamento da safra pelo porto de Itaqui, localizado em São Luís, MA. 
Além disso, encontram-se também solos com aptidão agrícola e condições climáticas favoráveis ao desenvolvimento das plantas.

Um dos principais nutrientes limitantes à produção nessas áreas é o P. Lopes \& Cox (1977) verificaram, em levantamento de caracterização dos solos de cerrado, que em $92 \%$ das amostras coletadas o teor disponível de $\mathrm{P}$ (Mehlich-1) foi inferior a $2 \mathrm{mg} \mathrm{dm}^{-3}$. Sousa et al. (2002) relataram a existência de resposta à aplicação de $\mathrm{P}$ até a dose de $300 \mathrm{~kg} \mathrm{ha}^{-1}$ de $\mathrm{P}_{2} \mathrm{O}_{5}$, o que evidencia, também, a baixa disponibilidade desse nutriente.

Os estudos com P, em condições de campo e em solos de cerrado, foram conduzidos, em sua maioria, nas regiões Sudeste e Centro-Oeste (Braga et al., 1980, 1991; Goedert \& Lobato, 1980; Coutinho et al., 1991; Motomiya et al., 2004; Resende et al., 2006). São raros, na literatura, os trabalhos relacionados à adubação fosfatada na região de Balsas e, quando existentes, estão relacionados à eficiência agronômica de fontes totalmente aciduladas de P (Sfredo et al., 1994, 1996). Entretanto, estudos com fontes alternativas de $\mathrm{P}$, tais como, os fosfatos naturais reativos, não foram publicados.

Este trabalho teve como objetivo principal avaliar a eficiência agronômica de um fosfato natural reativo, tendo-se como referência o superfosfato triplo.

\section{Material e Métodos}

O experimento foi instalado em Balsas, MA, em área da Agropecuária Serra Grande (Fazenda Agro Serra). A área experimental está a $6^{\circ} 46^{\prime} 8^{\prime \prime} \mathrm{S}$ e $45^{\circ} 45^{\prime} 50^{\prime \prime} \mathrm{W}$. O solo foi classificado como Latossolo VermelhoAmarelo distrófico (LVAd), com textura argilosa (510 $\mathrm{g} \mathrm{kg}^{-1}$ de argila), teor de P disponível de $2 \mathrm{mg} \mathrm{dm}^{-3}$ (resina) e capacidade máxima de fixação de $\mathrm{P}$ (isoterma de Langmuir) de $0,776 \mathrm{mg} \mathrm{g}^{-1}$. A área foi desmatada em 2000/2001 e em outubro de 2001 foi realizada a calagem, com $8 \mathrm{Mg} \mathrm{ha}^{-1}$ de calcário dolomítico (PRNT $=70 \%$ ), dose suficiente para elevar o $\mathrm{pH}$ em água para 5,5, aproximadamente, e a saturação por bases para $60 \%$.
Após a calagem, a área permaneceu em pousio até a instalação do experimento, em outubro de 2004.

O esquema experimental foi um fatorial $[(2 \times 2 \times 3)+2]$, com duas formas de aplicação (a lanço e em sulco de semeadura), duas fontes de P (superfosfato triplo - SFT e fosfato natural reativo Arad - FR) e três doses de $\mathrm{P}$ $\left(100,200\right.$ e $400 \mathrm{~kg} \mathrm{ha}^{-1}$ de $\left.\mathrm{P}_{2} \mathrm{O}_{5}\right)$. Os dois tratamentos adicionais corresponderam ao controle (sem $\mathrm{P})$ e à aplicação de $50 \mathrm{~kg} \mathrm{ha}^{-1}$ de $\mathrm{P}_{2} \mathrm{O}_{5}$, na forma de SFT, localizado no sulco de semeadura. O delineamento experimental utilizado foi o de blocos completamente casualizados, com três repetições. A área total das parcelas foi de $72 \mathrm{~m}^{2}$ (6x12 m), com 15 linhas de soja espaçadas em $0,40 \mathrm{~m}$. A área útil das parcelas, por sua vez, foi de $12 \mathrm{~m}^{2}(2,4 \times 5 \mathrm{~m})$.

Foram realizados três cultivos consecutivos de soja, em sistema convencional, nos anos agrícolas (safras) 2004/2005, 2005/2006 e 2006/2007, com a cultivar BRS Sambaíba. Os tratamentos foram aplicados durante os dois primeiros cultivos e, no terceiro cultivo, foi avaliado o efeito residual. Considerando-se que, para fins de cálculo do efeito residual, é necessário haver a aplicação do nutriente dentro do ano de estudo (Pimentel-Gomes \& Conagin, 1991), foi realizada a reaplicação da curva de resposta a P, na forma de SFT a lanço, tendo-se subdividido as respectivas parcelas.

A quantidade de SFT aplicada foi calculada com base no teor de $\mathrm{P}$ solúvel em CNA+água $\left(41,5 \%\right.$ de $\left.\mathrm{P}_{2} \mathrm{O}_{5}\right)$, enquanto a quantidade de FR foi determinada a partir do teor de $\mathrm{P}$ total $\left(33,3 \%\right.$ de $\left.\mathrm{P}_{2} \mathrm{O}_{5}\right)$. Na aplicação a lanço, os fertilizantes foram distribuídos manualmente na área total da parcela, e incorporados ao solo à profundidade média de $20 \mathrm{~cm}$, por meio de gradagem no sentido da semeadura. A aplicação localizada também foi realizada manualmente, tendo-se distribuído homogeneamente o fertilizante no fundo dos sulcos de semeadura.

As doses de K, S e micronutrientes utilizadas, bem como a data de semeadura em cada safra, estão apresentadas na Tabela 1. O S e os micronutrientes foram aplicados somente no primeiro ano de cultivo, em doses suficientes

Tabela 1. Datas de semeadura e adubações realizadas nos três cultivos de soja.

\begin{tabular}{|c|c|c|c|c|c|c|c|c|c|}
\hline \multirow[t]{3}{*}{ Safra } & \multirow[t]{3}{*}{ Data de semeadura } & \multicolumn{8}{|c|}{ Adubação de semeadura $^{(1)}$} \\
\hline & & $\mathrm{K}_{2} \mathrm{O}$ & $\mathrm{S}$ & $\mathrm{Zn}$ & $\mathrm{Mn}$ & $\mathrm{Cu}$ & B & Mo & $\mathrm{Co}$ \\
\hline & & & & 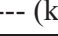 & & & 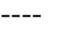 & $\cdots$ & --- \\
\hline $2004 / 2005$ & $19 / 12 / 2004$ & 100 & 150 & 5 & 5 & 5 & 2,5 & 150 & 15 \\
\hline $2005 / 2006$ & $17 / 12 / 2005$ & 80 & 0 & 0 & 0 & 0 & 0,0 & 0 & 0 \\
\hline $2006 / 2007$ & $11 / 12 / 2006$ & 80 & 0 & 0 & 0 & 0 & 0,0 & 0 & 0 \\
\hline
\end{tabular}

${ }^{(1)} \mathrm{K}_{2} \mathrm{O}$, cloreto de potássio; $\mathrm{S}$, enxofre elementar; $\mathrm{Zn}, \mathrm{Mn}, \mathrm{Cu}$ e Co, na forma de sulfatos; $\mathrm{B}$, ácido bórico; Mo, molibdato de sódio. 
para manutenção da disponibilidade adequada nos cultivos seguintes (Embrapa, 2003). Foram distribuídas cerca de 25-30 sementes por metro linear de sulco, com posterior desbaste para dez plantas por metro. As sementes foram tratadas com inoculantes, fungicidas e inseticidas, de acordo com a recomendação técnica oficial para a cultura da soja; além disso, quando necessário, os procedimentos de controle de plantas daninhas, pragas e doenças também foram realizados com os produtos apropriados e oficialmente recomendados em Embrapa (2003).

O regime pluviométrico durante a condução das três safras foi suficiente para o desenvolvimento adequado das plantas (Figura 1), e os valores acumulados entre dezembro e junho variaram entre 800 e $1.500 \mathrm{~mm}$. Apesar da variação no total acumulado, a distribuição dentro de cada mês foi uniforme, não tendo sido observados períodos de estiagem que pudessem comprometer os resultados.

No primeiro cultivo (safra 2004/2005), foi avaliada a produção de matéria seca da parte aérea (MSPA), tendose coletado 15 plantas na área útil das parcelas, cortadas rente à superfície do solo, no estádio fenológico $\mathrm{R}_{2}$ (florescimento pleno). As amostras foram secadas em estufa de circulação forçada de ar a $55^{\circ} \mathrm{C}$ até atingir massa constante, tendo-se procedido, então, à pesagem e à moagem. A digestão das amostras foi realizada por via úmida (digestão nítrico-perclórica, 3:1 v/v), e a determinação do teor de $\mathrm{P}$ foi realizada por meio do método colorimétrico do metavanadato (Malavolta et al., 1997). A partir da produção de MSPA e do teor de P na MSPA, foi possível calcular o conteúdo de P na MSPA (P acumulado).

Para avaliar a produtividade de grãos, colheram-se seis linhas de soja com $5 \mathrm{~m}$ de comprimento cada. Nas parcelas divididas, colheram-se três linhas, também com $5 \mathrm{~m}$ de comprimento.

A análise estatística dos resultados foi realizada por meio de análise de variância e regressões com o uso do SAS (SAS Institute, 1985). Para se calcular a eficiência agronômica relativa (EAR) das fontes, preliminarmente foram ajustados modelos de regressão linear múltipla, com variáveis "dummy" (Prochnow et al., 2003). Esse método possibilita que o modelo ajustado apresente um intercepto $\left(\beta_{0}\right)$ comum a todas as fontes, ao passo que os coeficientes angulares $\left(\beta_{1}\right)$ do modelo representam a resposta da planta, em função das doses de $\mathrm{P}$, com uma fonte e em uma determinada forma de aplicação.

Dessa forma, na análise de regressão relacionaram-se as variáveis dependentes (p.e. produtividade de grãos e $\mathrm{P}$ acumulado) com as doses de $\mathrm{P}$ aplicadas na forma de FR (a lanço e no sulco) e na forma de SFT, também a lanço e no sulco, com a condição padrão de comparação representada pela aplicação do SFT no sulco. Foram testados três modelos - linear, semi-raiz quadrático e logarítmico-, tendo-se optado por aquele com melhor ajuste. A EAR é obtida a partir da razão entre os valores dos $\beta_{1}$ :

$\operatorname{EAR}(\%)=\frac{\beta_{1 \text { Fonte i }}}{\beta_{1 \text { Fonte-padrão }}} \times 100$

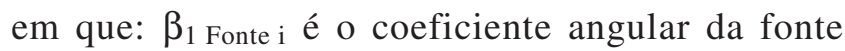
testada de P, p.e. o FR aplicado a lanço; $\beta_{1}$ Fonte-padrão é o coeficiente angular da fonte-padrão de $\mathrm{P}$, nesse caso,
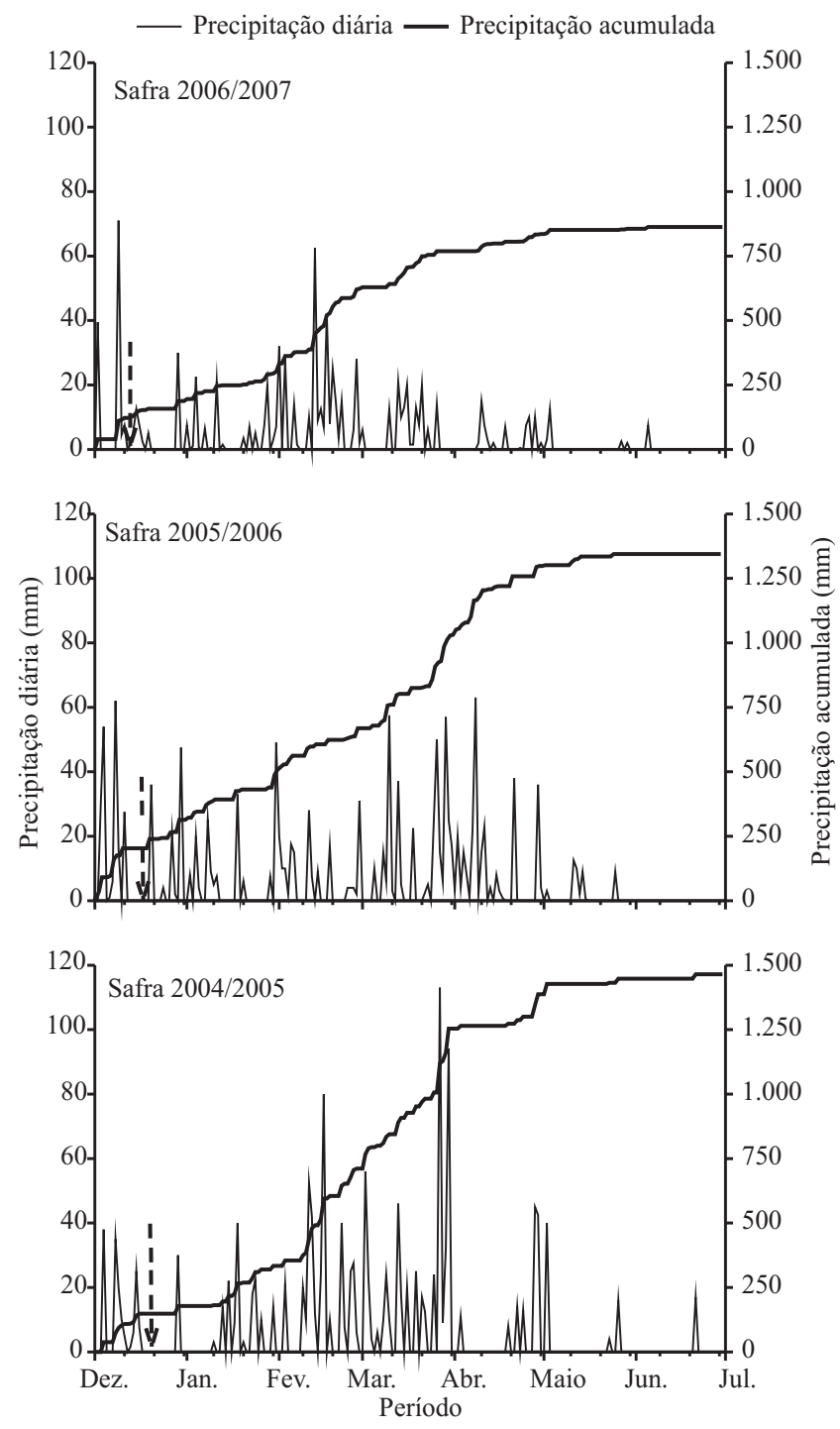

Figura 1. Dados pluviométricos, referentes às três safras em que o experimento foi conduzido. As setas indicam a data de semeadura. 
o SFT aplicado no sulco de semeadura. A comparação estatística dos valores dos coeficientes angulares $\left(\beta_{1}\right)$ foi realizada por meio do teste $F$ (Prochnow et al., 2003).

É importante ressaltar que para as duas primeiras safras (2004/2005 e 2005/2006), o modelo de regressão foi ajustado em função de quatro parâmetros (SFT sulco, SFT lanço, FR sulco e FR lanço), em que o padrão de comparação foi o SFT no sulco. Em 2006/2007, sob efeito residual, o modelo foi ajustado em função de cinco parâmetros, ou seja, além dos quatro anteriormente mencionados, houve um parâmetro adicional representado pela reaplicação do SFT a lanço, e esse o parâmetro foi utilizado como padrão de comparação durante a safra mencionada.

Especificamente para a safra 2006/2007, a EAR também foi calculada isoladamente para cada dose de $\mathrm{P}$, de acordo com a seguinte equação:

$\operatorname{EAR}(\%)=\frac{Y_{\text {Fonte i }}-\mathrm{Y}_{\text {Testemunha }}}{\mathrm{Y}_{\text {Fonte-padrão }}-\mathrm{Y}_{\text {Testemunha }}} \times 100$

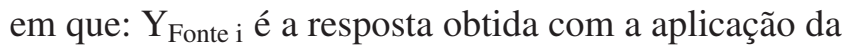
Fonte i, em uma determinada dose; Y Fonte-padrão é a resposta obtida com a aplicação da fonte-padrão de $\mathrm{P}$ (SFT lanço), em uma determinada dose; $\mathrm{Y}_{\text {Testemunha }}$ é a resposta obtida sem a aplicação de fósforo. Os valores de EAR foram relacionados, por meio de regressão linear simples, com as respectivas doses de fósforo. Isso possibilitou modelar a EAR das duas fontes, nas duas formas de aplicação, em função do efeito residual das doses de P.

\section{Resultados e Discussão}

Na safra 2004/2005, em que foi avaliada a MSPA e o P acumulado na MSPA, observou-se que, para ambas as variáveis, o modelo de regressão que melhor explicou a tendência foi o semi-raiz quadrático. Não foram observadas diferenças entre os parâmetros da regressão quanto à forma de aplicação do SFT (lanço e sulco), ao passo que em relação ao FR, a aplicação a lanço foi superior à aplicação localizada (Tabela 2 e Figura 2). Entretanto, o FR não foi semelhante ao SFT em produzir resposta, independentemente da forma de aplicação da fonte solúvel. Em termos de EAR, calculada com base na MSPA e no P acumulado, observou-se que a aplicação a lanço do SFT resultou, respectivamente, em $91 \%$ e em 108\% de EAR; a aplicação do FR, também a lanço, resultou em $53 \%$ e em $61 \%$, enquanto os valores obtidos com a aplicação localizada do FR foram de $14 \%$ e de $17 \%$ somente (Tabela 2).

No caso da produtividade de soja, nas duas safras em que houve a aplicação das fontes, os resultados foram muito semelhantes aos obtidos com as variáveis MSPA e $\mathrm{P}$ acumulado. $\mathrm{O}$ modelo matemático que melhor explicou a relação entre a produtividade e as doses de $\mathrm{P}$ foi o semi-raiz quadrático (Tabela 3 e Figura 3), não tendo sido observado novamente, diferenças entre as formas de aplicação do SFT. Resultados semelhantes foram verificados por Motomiya et al. (2004) para a soja, cultivada em solo de textura média, e por Resende et al. (2006) ao final de três cultivos consecutivos de milho em solo de textura argilosa (560 $\mathrm{g} \mathrm{kg}^{-1}$ de argila).

Assim, com a aplicação a lanço do SFT, apesar do maior contato do fertilizante com o solo, que notadamente pode

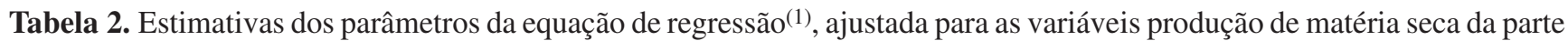
aérea (MSPA) e P acumulado na MSPA, em função da doses de P aplicadas, além dos respectivos valores de eficiência agronômica relativa $(\mathrm{EAR})^{(2)}$.

\begin{tabular}{|c|c|c|c|c|c|c|}
\hline \multirow[t]{2}{*}{ Fonte de $\mathrm{P}^{(3)}$} & \multirow{2}{*}{$\begin{array}{l}\text { Forma de } \\
\text { aplicação }\end{array}$} & \multirow[t]{2}{*}{ Parâmetro } & \multicolumn{2}{|l|}{ MSPA } & \multicolumn{2}{|c|}{$\mathrm{P}$ acumulado } \\
\hline & & & Estimativa dos parâmetros & EAR $(\%)$ & Estimativa dos parâmetros & EAR $(\%)$ \\
\hline & & $\beta_{0}$ & 199,0000 & & 0,2500 & \\
\hline SFT & Sulco & $\beta_{1}$ & $77,2918^{* *} \mathrm{~A}$ & 100 & $0,1531^{* *} \mathrm{~A}$ & 100 \\
\hline SFT & Lanço & $\beta_{2}$ & $70,3433^{* *} \mathrm{~A}$ & 91 & $0,1659^{* *} \mathrm{~A}$ & 108 \\
\hline FR & Lanço & $\beta_{3}$ & $40,6157^{* *} \mathrm{~B}$ & 53 & $0,0937^{* *} \mathrm{~B}$ & 61 \\
\hline FR & Sulco & $\beta_{4}$ & $10,7836^{*} \mathrm{C}$ & 14 & $0,0260^{*} \mathrm{C}$ & 17 \\
\hline CV $(\%)$ & & & 12,2 & & 13,7 & \\
\hline $\mathrm{R}^{2}$ & & & 0,99 & & 0,99 & \\
\hline Desvio-padr & da regressão & & 106,0 & & 0,2 & \\
\hline Erro-padrão & ss parâmetros & & 4,0 & & 0,008 & \\
\hline
\end{tabular}

${ }^{(1)}$ Modelo semi-raiz quadrático para ambas as variáveis. ${ }^{(2)}$ Valores seguidos de letras iguais, nas colunas, não diferem entre si, na comparação entre os estimadores do modelo de regressão pelo teste $\mathrm{F}$, a $5 \%$ de probabilidade. ${ }^{(3)}$ SFT: superfosfato triplo; FR: fosfato natural reativo Arad. * e **Significativo a 5 e $1 \%$ de probabilidade, respectivamente, pelo teste t da regressão. 


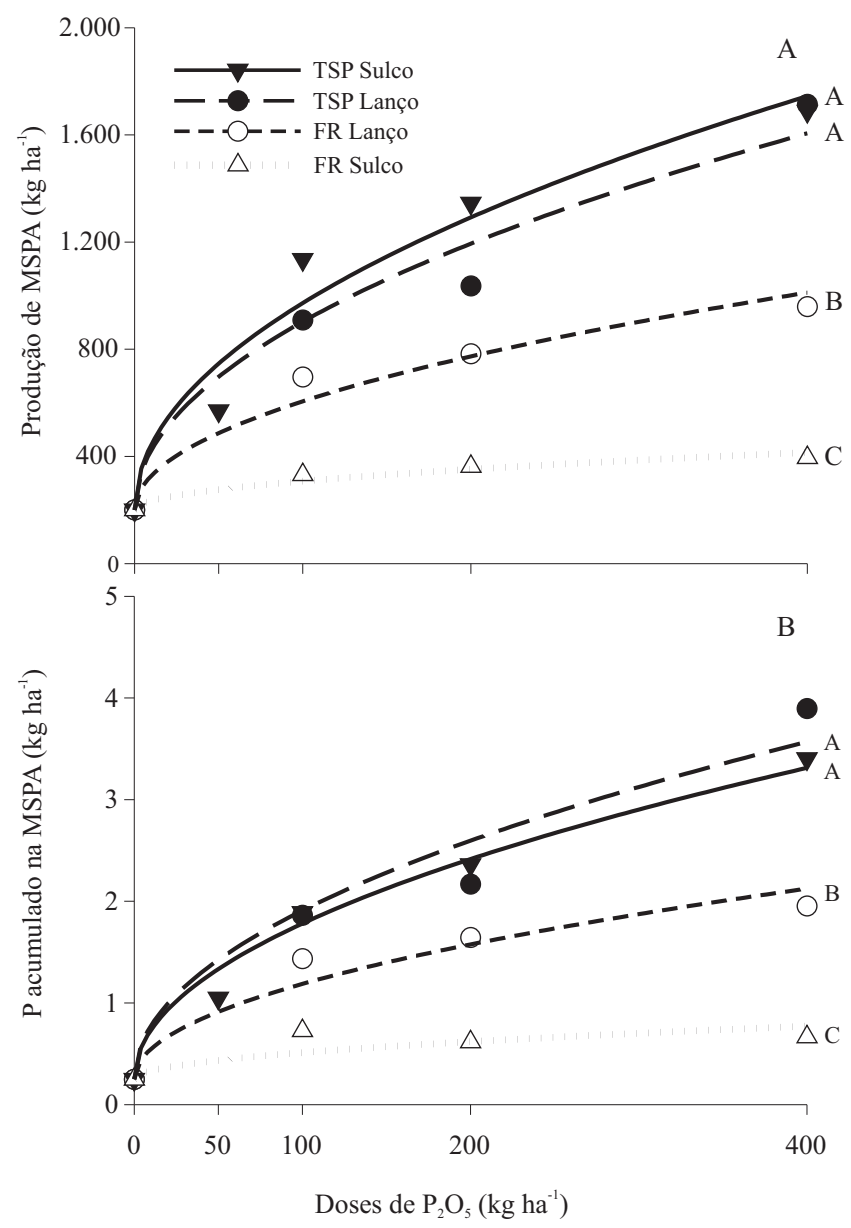

Figura 2. Efeito das doses e das fontes de P, aplicadas a lanço ou no sulco de semeadura, na produção de matéria seca da parte aérea (MSPA) (A) e no P acumulado na MSPA (B) das plantas de soja avaliadas no estádio $R_{2}$. Modelos seguidos de letras iguais não diferem entre si pelo teste $\mathrm{F}$, a $5 \%$ de probabilidade. levar à maior perda do $\mathrm{P}$ aplicado por processos de adsorção/ precipitação (Sample et al., 1980; Novais \& Smyth, 1999), é possível que ocorra, também, a maior exploração do volume de solo da camada arável pelas raízes das plantas, o que resulta em maior acúmulo de $\mathrm{P}$ por unidade de raiz, tal qual observado por Klepker \& Anghinoni (1995), o que compensaria os processos relacionados à formação de P não lábil.

Em relação ao FR, a aplicação a lanço resultou em resposta superior à aplicação no sulco, resultados esses que, uma vez mais, comprovam a necessidade de contato entre o solo e a rocha fosfática, para aumentar a taxa de dissolução da rocha e, conseqüentemente, fornecer quantidades de $\mathrm{P}$ suficientes para o desenvolvimento das plantas (Chien \& Menon, 1995a, 1995b; Rajan et al., 1996; Horowitz \& Meurer, 2004). Khasawneh \& Doll (1978) mencionaram que a aplicação a lanço e incorporação do FR é o método mais apropriado, pois promove a melhor distribuição dessa fonte na camada superficial do solo e, por consequiência, o maior contato entre a superfície das raízes e as partículas do FR. Todavia, a aplicação à lanço do FR não resultou em resposta estatisticamente semelhante à obtida com o SFT, mesmo com a reaplicação das doses, na safra 2005/2006 (Tabela 3). Menor eficiência agronômica para a aplicação localizada de fosfatos de rocha reativos foram observadas por Motomiya et al. (2004) e por Resende et al. (2006), respectivamente para a soja (FR Gafsa) e para o milho (FR Arad).

Em relação à EAR, foram observados valores muito próximos em ambas as safras, exceção feita à aplicação localizada do FR que, na safra 2005/2006 (segundo cultivo), resultou em $45 \%$ de EAR, ao passo que a EAR na safra

Tabela 3. Estimativas dos parâmetros da equação de regressão ${ }^{(1)}$, ajustada para a variável produtividade, nas safras $2004 / 2005$ e 2005/2006, em função da doses de P aplicadas, e os respectivos valores de eficiência agronômica relativa (EAR) ${ }^{(2)}$.

\begin{tabular}{|c|c|c|c|c|c|c|}
\hline \multirow{2}{*}{$\begin{array}{c}\text { Fonte de } \\
\mathrm{P}^{(3)}\end{array}$} & \multirow{2}{*}{$\begin{array}{l}\text { Forma de } \\
\text { aplicação }\end{array}$} & \multirow[t]{2}{*}{ Parâmetro } & \multicolumn{2}{|c|}{ Produtividade (2004/2005) } & \multicolumn{2}{|c|}{ Produtividade (2005/2006) } \\
\hline & & & Estimativa dos parâmetros & EAR $(\%)$ & Estimativa dos parâmetros & EAR $(\%)$ \\
\hline - & - & $\beta_{0}$ & 69,000 & & 129,000 & \\
\hline SFT & Sulco & $\beta_{1}$ & $157,482^{* *} \mathrm{~A}$ & 100 & $159,913^{* *} \mathrm{~A}$ & 100 \\
\hline SFT & Lanço & $\beta_{2}$ & $167,623^{* *} \mathrm{~A}$ & 106 & $168,180^{* *} \mathrm{~A}$ & 105 \\
\hline FR & Lanço & $\beta_{3}$ & $117,943^{* *} \mathrm{~B}$ & 75 & $124,989^{* *} \mathrm{~B}$ & 78 \\
\hline FR & Sulco & $\beta_{4}$ & $28,681^{* *} \mathrm{C}$ & 17 & $72,531^{* *} \mathrm{C}$ & 45 \\
\hline \multicolumn{3}{|l|}{ CV (\%) } & 11,6 & & 13,2 & \\
\hline & 0,99 & & 0,99 & \\
\hline \multirow{2}{*}{\multicolumn{3}{|c|}{ Desvio-padrão da regressão }} & 188,9 & & 249,8 & \\
\hline & & Erro-padrão dos parâmetros & 7,14 & & 9,44 & \\
\hline
\end{tabular}

${ }^{(1)}$ Modelo semi-raiz quadrático para ambas as variáveis. (2) Valores seguidos de letras iguais, nas colunas, não diferem entre si, na comparação entre os estimadores do modelo de regressão pelo teste F, a 5\% de probabilidade. ${ }^{(3)}$ SFT: superfosfato triplo; FR: fosfato natural reativo Arad. * e **Significativo a 5 e $1 \%$ de probabilidade, respectivamente, pelo teste $\mathrm{t}$ da regressão. 


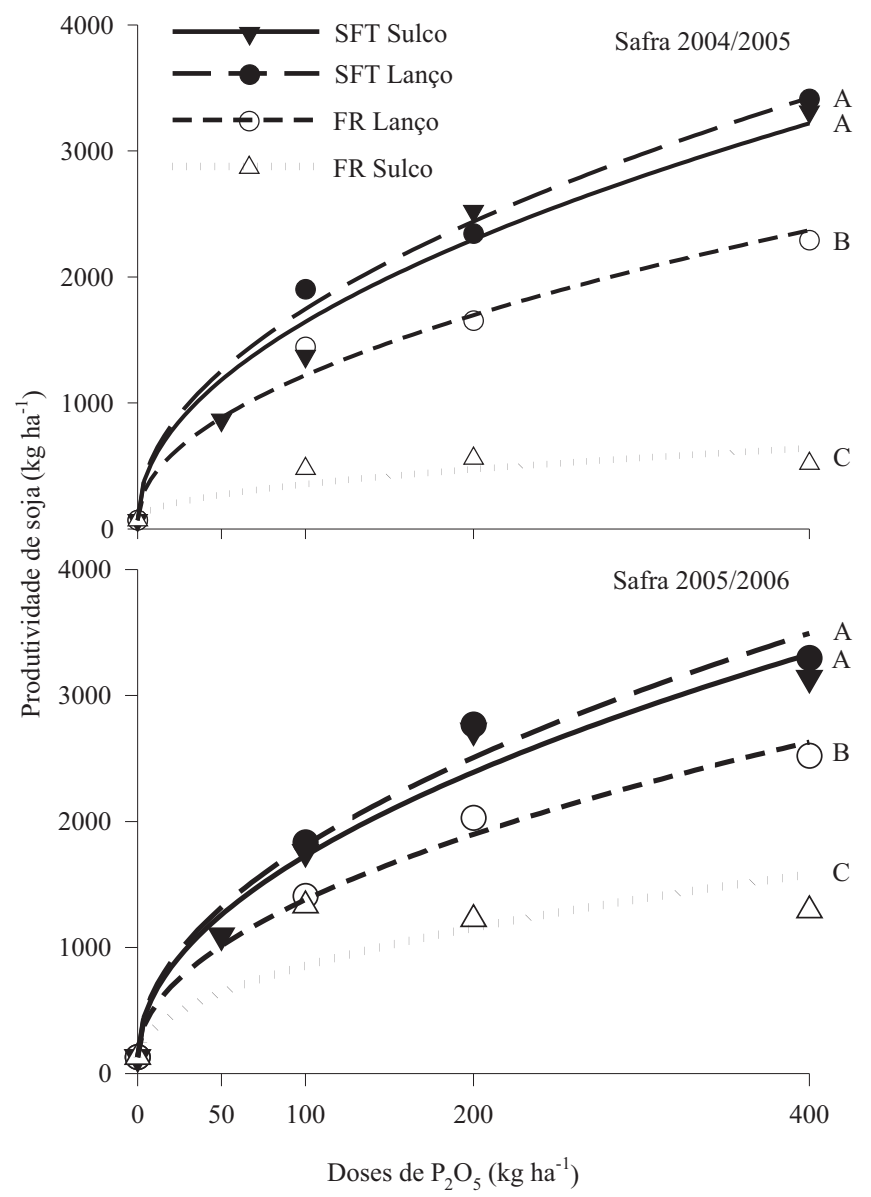

Figura 3. Efeito das doses e das fontes de P, aplicadas a lanço ou no sulco de semeadura, na produtividade de grãos de soja durante as safras 2004/2005 e 2005/2006. Modelos seguidos de letras iguais não diferem entre si pelo teste $\mathrm{F}$, a $5 \%$ de probabilidade. anterior foi de somente $17 \%$ (Tabela 3). Esse aumento se deve, provavelmente, ao efeito residual do $P$ aplicado no ano anterior, bem como, à incorporação do FR ao solo, com o preparo (gradagem) realizado para o segundo cultivo.

A EAR do FR aplicado a lanço foi de 75 e $78 \%$, nas safras 2004/2005 e 2005/2006, respectivamente (Tabela 3). Isso demonstra que os fosfatos naturais de elevada reatividade, quando utilizados sob condições que promovam sua maior eficiência, podem suprir grande parte da demanda da planta por $\mathrm{P}$, já no primeiro ano de cultivo, e essas fontes podem ser utilizadas eficientemente na adubação corretiva a lanço, desde que seus preços sejam viáveis em termos econômicos, conforme mencionado por Sousa \& Lobato (2003).

Na avaliação do efeito residual, na safra 2006/2007, o modelo que melhor explicou a relação entre a produtividade e as doses de $\mathrm{P}$ foi, mais uma vez, o semi-raiz quadrático (Tabela 4 e Figura 4). É importante ressaltar, que em razão da igualdade entre as formas de aplicação do SFT, durante a fase de aplicação, optou-se por reaplicar essa fonte a lanço, condição que foi utilizada como padrão de referência no cálculo do efeito residual. Assim, a aplicação localizada do SFT resultou em $92 \%$ de eficiência agronômica relativa sob efeito residual (EARr), não tendo diferido estatisticamente da reaplicação de P em 2006/2007 (Tabela 4). Quando o SFT foi aplicado a lanço, a EARr foi de $77 \%$, ou seja, o maior contato entre o solo e o fertilizante levou à diminuição de $15 \%$ na EARr do SFT, embora não tenha sido verificada diferença estatística entre as formas de aplicação dessa fonte.

Tabela 4. Estimativas dos parâmetros da equação de regressão(1) , ajustada para a variável produtividade, na safra 2006/2007, em função da doses de $\mathrm{P}$ aplicadas nas safras anteriores, e os respectivos valores de eficiência agronômica relativa sob efeito residual $(\mathrm{EARr})^{(2)}$.

\begin{tabular}{|c|c|c|c|c|c|}
\hline \multirow{2}{*}{$\begin{array}{c}\text { Fonte de } \\
\mathrm{P}^{(3)} \\
\end{array}$} & \multirow{2}{*}{$\begin{array}{l}\text { Forma de } \\
\text { aplicação }\end{array}$} & \multirow[t]{2}{*}{ Histórico de aplicação } & \multirow[t]{2}{*}{ Parâmetro } & \multicolumn{2}{|c|}{ Produtividade (2006/2007) } \\
\hline & & & & Estimativa dos parâmetros & EARr $(\%)$ \\
\hline & & & $\beta_{0}$ & 147,000 & \\
\hline SFT & Lanço & $2004,2005,2006$ & $\beta_{1}$ & $189,387^{* *} \mathrm{~A}$ & 100 \\
\hline SFT & Sulco & 2004, 2005 & $\beta_{2}$ & $174,226^{* *} \mathrm{AB}$ & 92 \\
\hline SFT & Lanço & 2004, 2005 & $\beta_{3}$ & $145,116^{* *} \mathrm{BC}$ & 77 \\
\hline FR & Lanço & 2004,2005 & $\beta_{4}$ & $148,540^{* *} \mathrm{BC}$ & 78 \\
\hline FR & Sulco & 2004, 2005 & $\beta_{5}$ & $133,593^{* *} \mathrm{C}$ & 71 \\
\hline \multicolumn{3}{|l|}{ CV (\%) } & & 13,4 & \\
\hline \multicolumn{3}{|c|}{$\mathrm{R}^{2}$} & & 0,99 & \\
\hline \multicolumn{3}{|c|}{ Desvio-padrão da regressão } & & 308,3 & \\
\hline \multicolumn{3}{|c|}{ Erro-padrão dos parâmetros } & & 11,65 & \\
\hline
\end{tabular}

${ }^{(1)}$ Modelo semi-raiz quadrático para ambas as variáveis. ${ }^{(2)}$ Valores seguidos de letras iguais, nas colunas, não diferem entre si, na comparação entre os estimadores do modelo de regressão pelo teste $\mathrm{F}$, a $5 \%$ de probabilidade. ${ }^{3}$ SFT: superfosfato triplo; FR: fosfato natural reativo Arad. **Significativo a $1 \%$ de probabilidade, pelo teste t da regressão. 


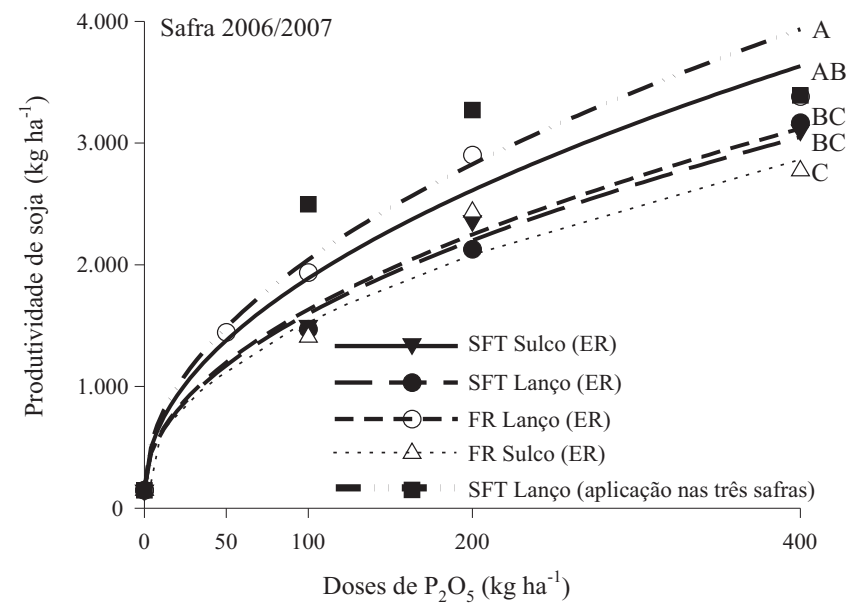

Figura 4. Efeito residual (ER) das doses e das fontes de P, aplicadas a lanço ou no sulco de semeadura durante as safras 2004/2005 e 2005/2006, na produtividade de grãos de soja na safra 2006/2007. Modelos seguidos de letras iguais não diferem entre si pelo teste $\mathrm{F}$, a $5 \%$ de probabilidade.

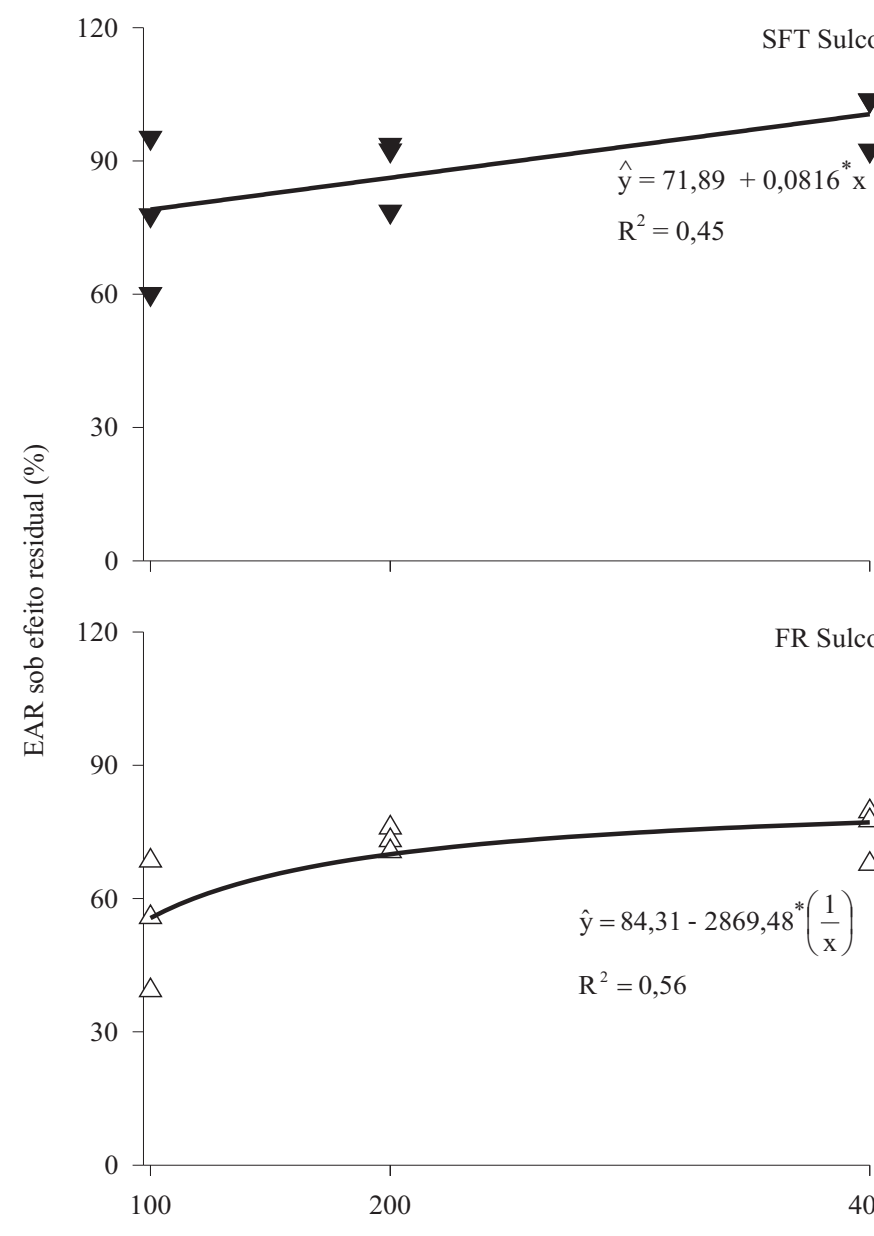

A EARr do FR foi de $71 \%$ e de $78 \%$, respectivamente, para a aplicação no sulco e a lanço, não tendo havido diferença estatística entre esses valores (Tabela 4). Isso indica que, com os cultivos, a eficiência agronômica do FR aplicado de forma localizada pode ser semelhante à obtida com a aplicação a lanço, desde que seja realizado o preparo do solo (sistema convencional de cultivo). Apesar de ter havido diferença estatística entre a reaplicação do SFT, em 2006/2007, e o efeito residual do FR, a obtenção de valores de EARr entre 70 e $80 \%$ indica a viabilidade de utilização desta fonte para a cultura da soja, desde que a diferença mínima entre o custo dessas fontes, inclusive a aplicação, esteja entre 20 e $30 \%$ a favor do FR.

Na Figura 5, podem-se visualizar os modelos ajustados para a EARr das fontes, calculada dentro de cada dose (Eq. 2), em função das respectivas doses aplicadas. $\mathrm{Na}$ prática, esses modelos possibilitaram avaliar a
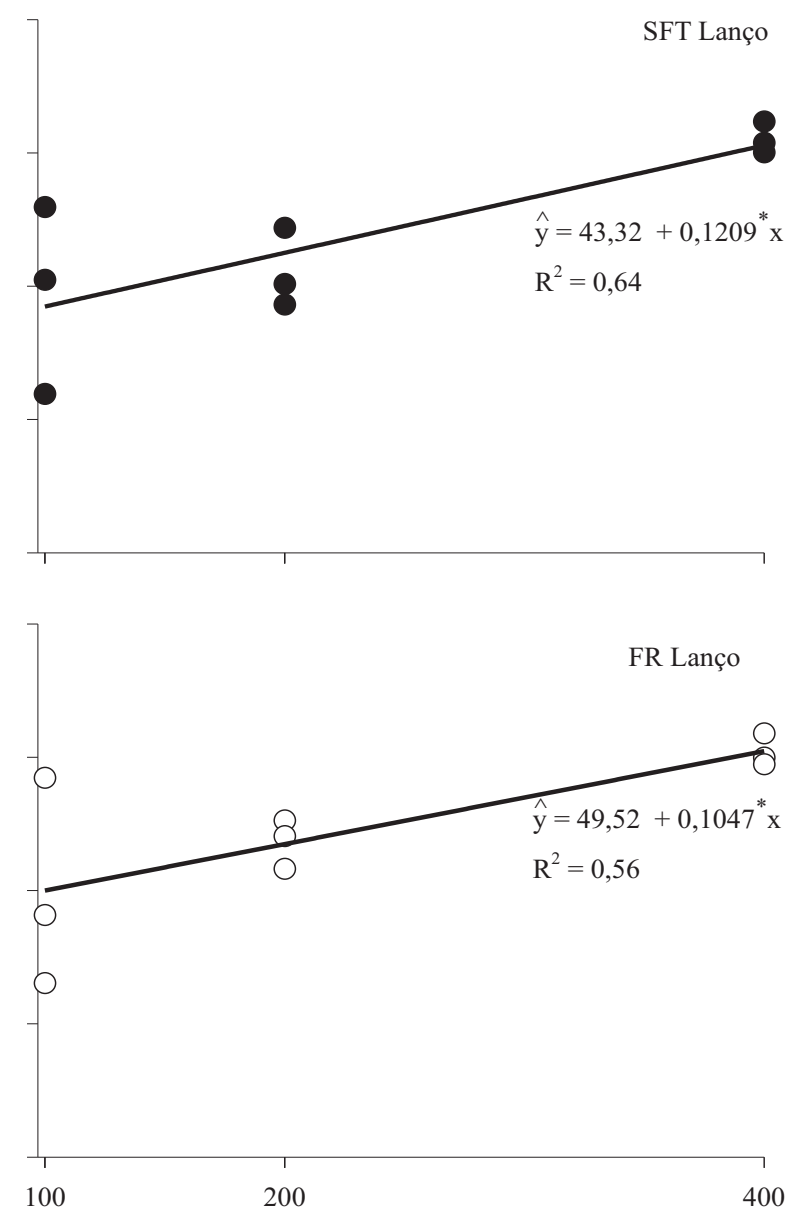

Doses de $\mathrm{P}_{2} \mathrm{O}_{5}\left(\mathrm{~kg} \mathrm{ha}^{-1}\right)$

Figura 5. Eficiência agronômica relativa (EAR) residual das fontes de P, na safra 2006/2007, em função das doses de $P$ aplicadas nas safras 2004/2005 e 2005/2006. EAR calculada em cada dose. 
resposta das plantas, tendo-se como base a EARr, às doses aplicadas nas duas safras anteriores. Dessa forma, para a aplicação localizada do FR, que na média das doses resultou em $71 \%$ de EARr (Tabela 3), observouse, ao se desdobrar o efeito das doses, o aumento da EARr até aproximadamente $200 \mathrm{~kg} \mathrm{ha}^{-1} \mathrm{de}_{2} \mathrm{O}_{5}$, o que indica que a aplicação de doses superiores a esta não resulta, necessariamente, em aumento na EAR sob efeito residual. Provavelmente, com a localização do FR, a cinética de dissolução desta fonte atingiu valor máximo (produto de solubilidade) com a aplicação de $200 \mathrm{~kg} \mathrm{ha}^{-1}$ de $\mathrm{P}_{2} \mathrm{O}_{5}$.

Essa tendência de estabilização, a partir de uma dada dose de P, não foi observada nem para a aplicação a lanço do FR, nem para o SFT, independentemente da forma de aplicação, visto que, nos três casos foram ajustados modelos lineares. Interpretando-se as equações lineares (Figura 5), pode-se dizer que a aplicação do SFT no sulco resultou no menor incremento na EARr com as doses, ou seja, menor declividade da reta $\left(\beta_{1}=0,082\right.$, que corresponde a $8,2 \%$ de aumento na EARr para cada $100 \mathrm{~kg} \mathrm{ha}^{-1}$ de $\mathrm{P}_{2} \mathrm{O}_{5}$ ), ao passo que as taxas obtidas com a aplicação a lanço do FR e do SFT foram, respectivamente, de 10,5 e 12,1\%. Maiores valores na declividade da reta, quando as fontes foram aplicadas a lanço, se relacionam à menor EARr na dose de $100 \mathrm{~kg} \mathrm{ha}^{-1}$ de $\mathrm{P}_{2} \mathrm{O}_{5}$ (55 e $59 \%$, respectivamente, para o SFT e o FR), fato esse que não foi observado na aplicação localizada do SFT que, para essa mesma dose, resultou em $80 \%$ de EARr.

\section{Conclusões}

1. A localização do superfosfato triplo não apresenta influência na produtividade de soja nem nas demais variáveis avaliadas.

2. A eficiência agronômica relativa do fosfato natural reativo aplicado a lanço é superior à verificada com a aplicação desta mesma fonte no sulco de semeadura; entretanto, não se iguala à obtida com o superfosfato triplo.

3. A aplicação localizada do superfosfato triplo, nas duas primeiras safras somente, resulta em resposta semelhante à obtida com a aplicação anual desta fonte; maiores incrementos na eficiência agronômica relativa residual ocorrem, quando as fontes são aplicadas a lanço.

\section{Referências}

BRAGA, N.R.; MASCARENHAS, H.A.A.; BULISANI, E.A.; RAIJ, B. van; FEITOSA, C.T.; HIROCE, R. Eficiência agronômica de nove fosfatos em quatro cultivos consecutivos de soja. Revista Brasileira de Ciência do Solo, v.15, p.315-319, 1991.

BRAGA, N.R.; MASCARENHAS, H.A.A.; FEITOSA, C.T.; HIROCE, R.; RAIJ, B. van. Efeitos de fosfatos sobre o crescimento e produção de soja. Revista Brasileira de Ciência do Solo, v.4, p.36-39, 1980.

CHIEN, S.H.; MENON, R.G. Agronomic evaluation of modified phosphate rock products. IFDC's experience. Fertilizer Research, v.41, p.197-209, 1995a.

CHIEN, S.H.; MENON, R.G. Factors affecting the agronomic effectiveness of phosphate rock for direct application. Fertilizer Research, v.41, p.227-234, 1995b.

CONAB. Acompanhamento da safra brasileira: grãos safra 2006/ 2007: décimo segundo levantamento: setembro de 2007. Brasília: Conab, 2007. Disponível em: http://www.conab.gov.br/conabweb/ download/safra/12_levantamento_set2007.pdf. Acesso em: 23 out. 2007.

COUTINHO, E.L.M.; NATALE, W.; VILLA NOVA, A.S.; SITTA, D.S.X. Eficiência agronômica de fertilizantes fosfatados para a cultura da soja. Pesquisa Agropecuária Brasileira, v.26, p.1393-1399, 1991.

EMBRAPA. Tecnologias de produção de soja: região central do Brasil. Londrina: Embrapa Soja; Brasília: Embrapa Cerrados; Dourados: Embrapa Agropecuária Oeste; Belo Horizonte: Epamig: Fundação Triângulo, 2003. 237p. (Sistemas de Produção, 11).

GOEDERT, W.J.; LOBATO, E. Eficiência agronômica de fosfatos em solo de cerrado. Pesquisa Agropecuária Brasileira, v.15, p.311$318,1980$.

HOROWITZ, N.; MEURER, E.J. Eficiência agronômica dos fosfatos naturais. In: YAMADA, T.; ABDALLA, S.R.S. (Ed.). Fósforo na agricultura brasileira. Piracicaba: Potafos, 2004. p.665-687.

KHASAWNEH, F.E.; DOLL, E.C. The use of phosphate rock for direct application to soils. Advances in Agronomy, v.30, p.159206, 1978.

KLEPKER, D.; ANGHINONI, I. Crescimento radicular e aéreo do milho em vasos em função do nível de fósforo no solo e da localização do adubo fosfatado. Revista Brasileira de Ciência do Solo, v.19, p.403-408, 1995.

LOPES, A.S.; COX, F.R. A survey of the fertility status of surface soils under "cerrado" vegetation in Brazil. Soil Science Society of American Journal, v.41, p.742-747, 1977.

MALAVOLTA, E.; VITTI, G.C.; OLIVEIRA, S.A. Avaliação do estado nutricional das plantas: princípios e aplicações. 2.ed. Piracicaba: Potafos, 1997. 201p.

MOTOMIYA, W.R.; FABRÍCIO, A.C.; MARCHETTI, M.E.; GONÇALVES, M.C.; ROBAINA, A.D.; NOVELINO, J.O. Métodos de aplicação de fosfato na soja em plantio direto. Pesquisa Agropecuária Brasileira, v.39, p.307-312, 2004.

NOVAIS, R.F.; SMYTH, T.J. Fósforo em solo e planta em condições tropicais. Viçosa: UFV, 1999. 399p. 
PIMENTEL-GOMES, F.; CONAGIN, A. Experimentos de adubação: planejamento e análise estatística. In: OLIVEIRA, A.J. de; GARRIDO, W.E.; ARAUJO, J.D. de; LOURENÇO, S. (Ed.). Métodos de pesquisa em fertilidade do solo. Brasília: EmbrapaSEA, 1991. p.103-188.

PROCHNOW, L.I.; CHIEN, S.H.; TAYLOR, R.W.; CARMONA, G.; HENAO, J.; DILLARD, E.F. Characterization and agronomic evaluation of single superphosphates varying in iron phosphate impurities. Agronomy Journal, v.95, p.293-302, 2003.

RAJAN, S.S.S.; WATKINSON, J.H.; SINCLAIR, A.G. Phosphate rocks for direct application to soils. Advances in Agronomy, v.57, p.77-159, 1996.

RESENDE, A.V. de; FURTINI NETO, A.E.; ALVES, V.M.C.; MUNIZ, J.A.; CURI, N.; FAQUIN, V.; KINPARA, D.I.; SANTOS, J.Z.L.; CARNEIRO, L.F. Fontes e modos de aplicação de fósforo para o milho em solo cultivado da Região do Cerrado. Revista Brasileira de Ciência do Solo, v.30, p.453-466, 2006.

SAMPLE, E.C.; SOPER, R.J.; RACZ, G.J. Reactions of phosphate fertilizers in soils. In: KHASAWNEH, F.E.; SAMPLE, E.C.;
KAMPRATH, E.J. (Ed.). The role of phosphorus in agriculture. Madison: American Society of Agronomy, 1980. p.263-310.

SAS INSTITUTE. SAS for linear models: a guide to the ANOVA and GLM procedures. Cary: Sas Institute, 1985.

SFREDO, G.J.; PALUDZYSZYN FILHO, E.; GOMES, E.R. Resposta da soja a potássio e a fósforo em Podzólico VermelhoAmarelo de Balsas, MA. Pesquisa Agropecuária Brasileira, v.29, p.1359-1364, 1994.

SFREDO, G.J.; PALUDZYSZYN FILHO, E.; GOMES, E.R.; OLIVEIRA, M.C.N. de. Resposta da soja a fósforo e a calcário em Podzólico Vermelho-Amarelo de Balsas, MA. Revista Brasileira de Ciência do Solo, v.20, p.429-432, 1996.

SOUSA, D.M.G. de; LOBATO, E. Adubação fosfatada em solos da Região do Cerrado. Informações Agronômicas Potafos, v.102, p.116, 2003.

SOUSA, D.M.G. de; LOBATO, E.; REIN, T.A. Adubação com fósforo. In: SOUSA, D.M.G. de; LOBATO, E. (Ed.). Cerrado: correção do solo e adubação. Planaltina: Embrapa Cerrados, 2002. p.147-168.

Recebido em 2 de dezembro de 2007 e aprovado em 23 de abril de 2008 